\title{
Development of an Organizational Maturity Model in Terms of Mass Customization
}

\author{
Vladimír Modrák and Zuzana Šoltysová
}

\subsection{Introduction}

Production technologies are, these days, mostly affected by dynamic development of information technology and automatic identification technologies. Obviously, technological changes are driven by many factors such as increasing requirements of individual customers, safety and environmental standards, social demands, the diffusion of disruptive innovations, and so on. In general, technology is changing very rapidly and the newest technological developments are reshaping the manufacturing sector in its original form. For example, additive manufacturing, cloud computing, radio frequency identification, fifth-generation wireless systems, and the Internet of Things (IoT) are only a few of the

\footnotetext{
V. Modrák $(\bowtie) \cdot Z$. Šoltysová

Department of Manufacturing Management, Technical University of Košice, Prešov, Slovakia e-mail: vladimir.modrak@tuke.sk

Z. Šoltysová

e-mail: zuzana.soltysova@tuke.sk

(C) The Author(s) 2020 
new technologies that are driving a paradigm shift in manufacturing. The umbrella term for this new wave of so-called smart manufacturing is Industry 4.0 (Kagermann et al. 2013). The main objectives of Industry 4.0 can be characterized, in a simple way, as the introduction of intelligent applications and smart sensor device in production, logistics and business models. Moreover, new information and communication technology (ICT) and web technologies act as enablers of smart, autonomous, and self-learning factories. According to some authors as Sommer (2015), Rauch et al. (2018), successful implementation of Industry 4.0 has to take place not only in large enterprises but in small- and medium-sized enterprises (SMEs) as well. Therefore, a great challenge for the future lies in the transfer of Industry 4.0 expertise and technologies to this size of manufacturing firms that represent the backbone of regional economies. Although there is high potential from Industry 4.0 in SMEs, the main limit lies in a lack of methodological frameworks for its introduction and wide implementation. In addition, a growing number of factories are facing the challenges of even more individualized and customized products (Modrak 2017). This is also the case among SMEs, which are involved in global business and facing a demand for increased product variety (Brunoe and Nielsen 2016). In this context, this chapter aims to help overcome this gap through proposed approaches and solutions.

The chapter is divided into several sections. After this section, the existing approaches to maturity models for the application of Industry 4.0 (I4.0) concept are presented and analyzed. Next, the problem description gives a short explanation of why managerial and organizational concepts, supporting models, and quantitative indicators can be helpful in the introduction of I4.0 in manufacturing companies. The methodological steps of the presented research are graphically depicted in Sect. 8.4. The development steps of the proposed maturity model (MM) are described in detail in the subsequent Sects. 8.5 and 8.6. This part of the chapter presents its main contribution to the managerial and organizational models for the introduction and implementation of I4.0 in terms of mass customization (MC). The final section offers future directions and summarizes the major results of this chapter. 


\subsection{Literature Review}

In general, advanced technologies, including those related to I4.0, infiltrate permanently into all spheres of human life in developed countries. On the other hand, Cotteleer and Sniderman (2017) argue that "there is little doubt that penetration of Industry 4.0 concept in companies' processes and operations will grow." Moreover, some authors (e.g., Hofmann and Rüsch 2017) were skeptical about companies' efforts in this area since according to them the "concept of Industry 4.0 still lacks a clear understanding." This corresponds with a limited occurrence of literature that deals with the concept of Industry 4.0 or smart manufacturing from methodological viewpoints and clarifies how to successfully implement the main components of I4.0 into manufacturing practice. Smart factories can be characterized by distinctive features that reflect different aspects of the domain of interest. According to Pessl et al. (2017) smart factories represents the connection between digital and physical production networks known also as cyber-physical systems. In particular, the integration of computing, wireless, and Internet technologies makes this connection possible. IoT is the most critical component for connecting devices without wired connection (Avram et al. 2017; Belforte and Eula 2012; Ahuett-Garza and Kurfess 2018). For this reason, some of the biggest challenges for manufacturing companies is to increase the level of digitization, to adapt production lines to new technologies or to define the role of humans within new processes (Fang et al. 2016). Toward these outcomes, different MMs can help to identify where the company currently operates and what needs to change. Moreover, maturity models offer comprehensive guidance and introduce and create a basis for evaluating the progress in the maturity of process or a technology. Most maturity models are dedicated to assessing people, culture, processes, structures, and objects or technology, respectively (Mettler 2011). Tavana (2012) pointed out that "the most important point of critique is the poor theoretical basis of maturity models." Becker et al. (2009) proposed evaluation criteria and a generic methodology for the development of maturity models and applied them to the maturity model for IT management. Several authors adopted 
their recommended steps for developing maturity models related to I4.0. For instance, Leyh et al. (2017) offered an MM for classifying the enterprise-wide IT and software Landscape from the I4.0 perspective, and recommended activities, which can enable a company to reach individual maturity stages. Similarly, Schumacher et al. (2016), and Sternad et al. (2018) have been inspired by their methodology and applied their recommendations to the development of Industry 4.0 related readiness and maturity models. Kese and Terstegen (2017) categorize four types of MM in terms of I4.0. Another classification concept was proposed by Barata and da Cunha (2017), who recommend classifying MM into two groups, i.e., practical models for specific applications or generic MM for I4.0 and its sub-domains. According to Fraser et al. (2002), it is also useful to distinguish between so-called maturity grids, capability MM models or Likert-like questionnaires MM.

In order to compare and analyze existing readiness maturity models, roadmaps, and conceptual frameworks related to Industry 4.0, it is useful to present them in a structural form by pointing out their relevant attributes. Related works with their characteristics are presented in Table 8.1.

Based on this review, the 20 identified and investigated literature sources were dedicated to one or more of three types of methods namely, I4.0 readiness MMs, roadmaps, and conceptual frameworks. It is necessary to note that specific capability maturity models can also be understood as evolutionary roadmaps for implementing the best practices or methodologies into company processes (Curtis et al. 2001). Here identified systematic roadmaps are presented in explicit form, and they might enable companies to answer questions about what technologies to develop when and how. The quantitative occurrence of each type of method was as follows: I4.0 MMs-17 literature sources, the roadmaps -5 literature sources, and the conceptual frameworks -5 papers.

The literature sources used in Table 8.1 can be classified into two basic categories: academic literature, and nonacademic literature. In general, journal papers and conference proceedings represent scientific research, and the latest developments in a specialized field (Wong and Monaco 1995). Rigorous academic books can be included in the first category, too. Then, the academic literature used in our review consists 


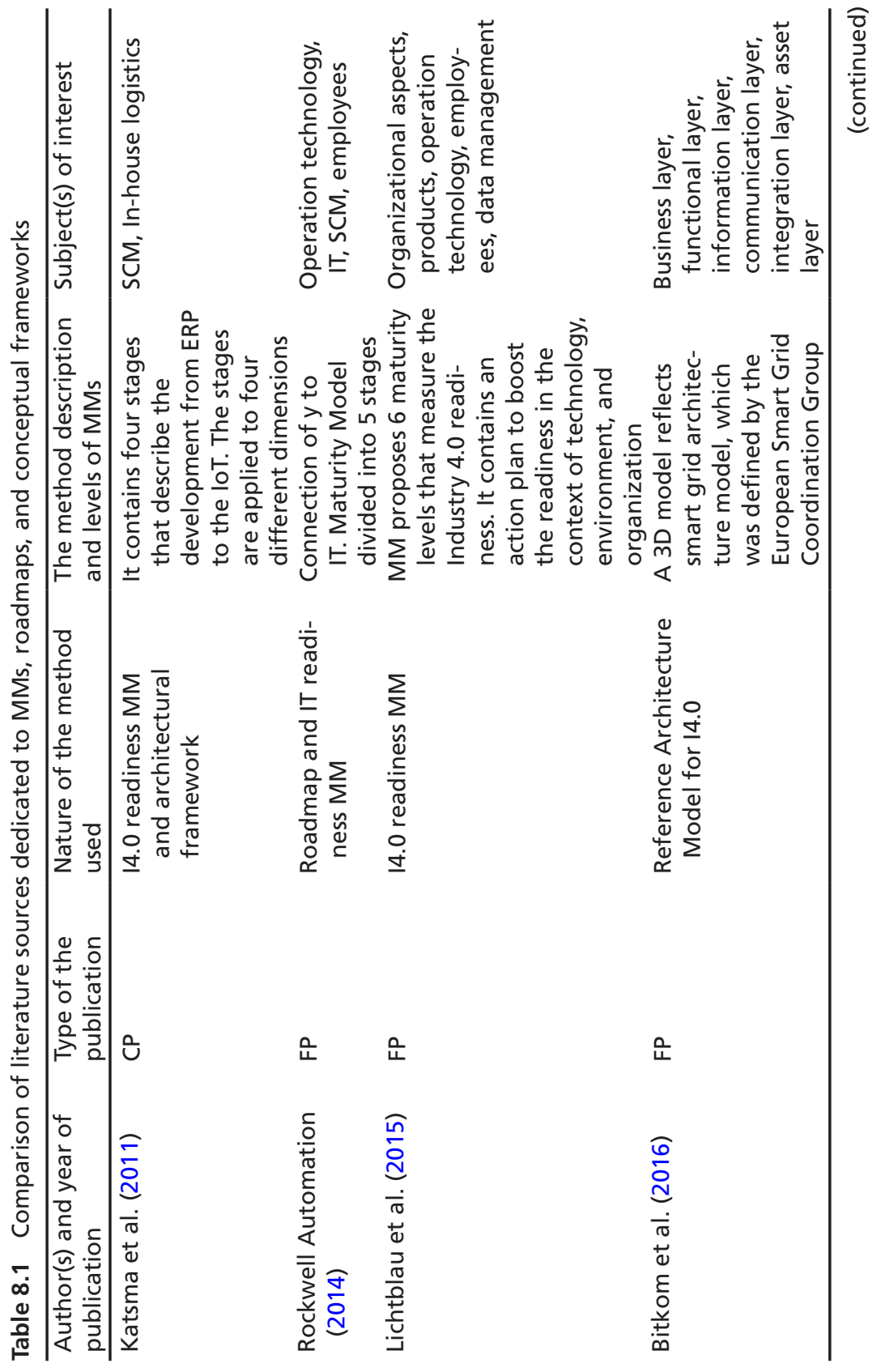




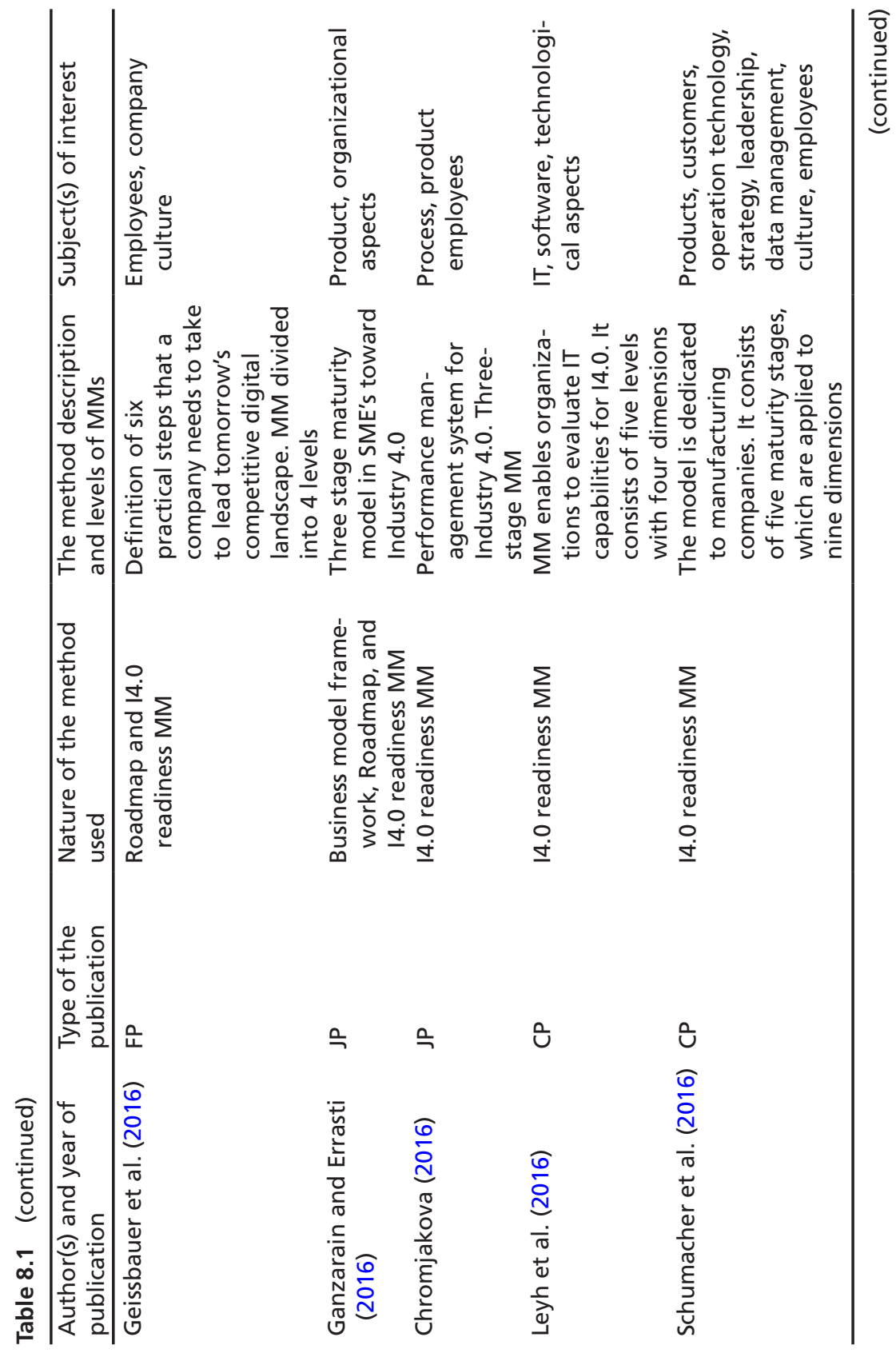




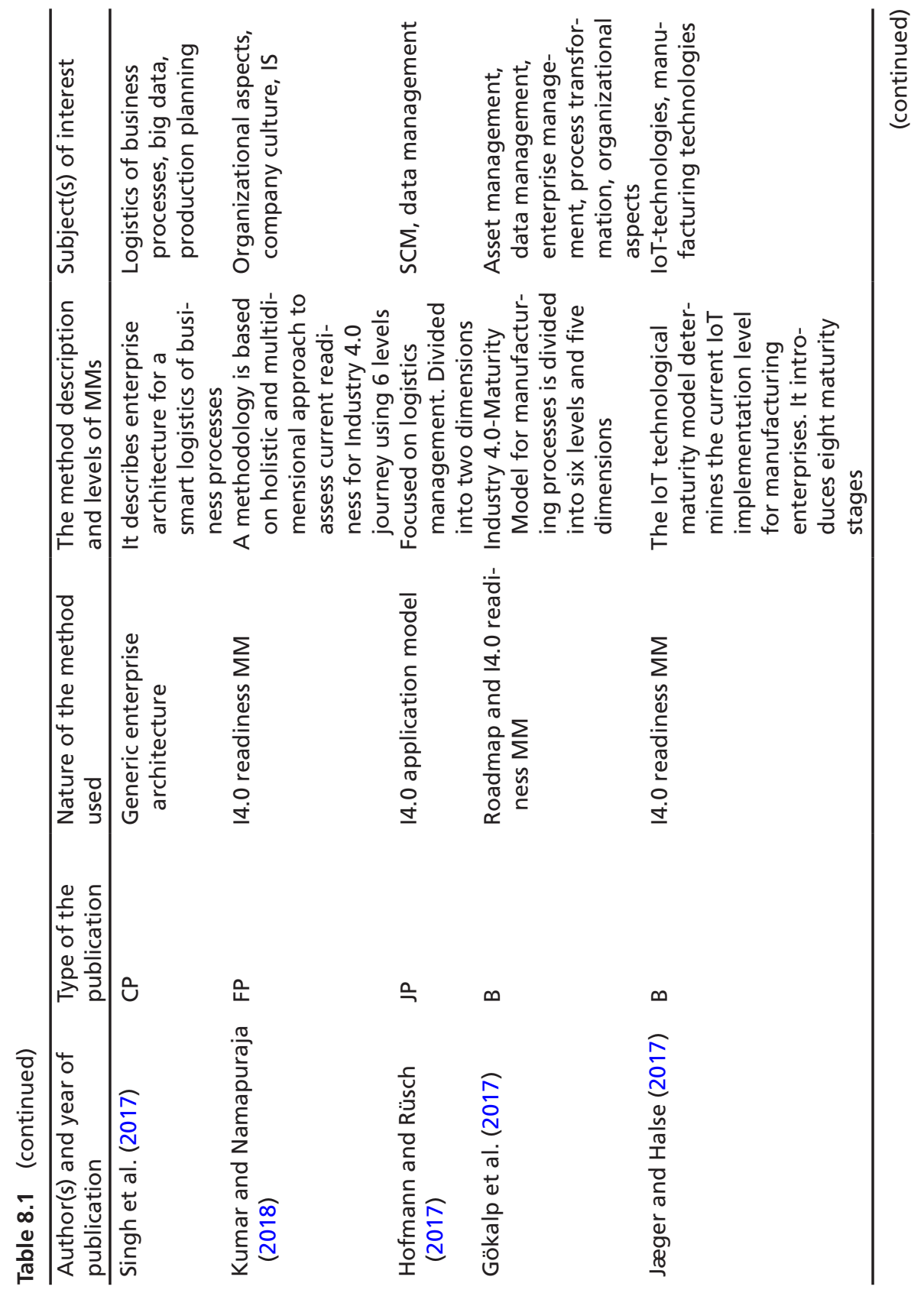




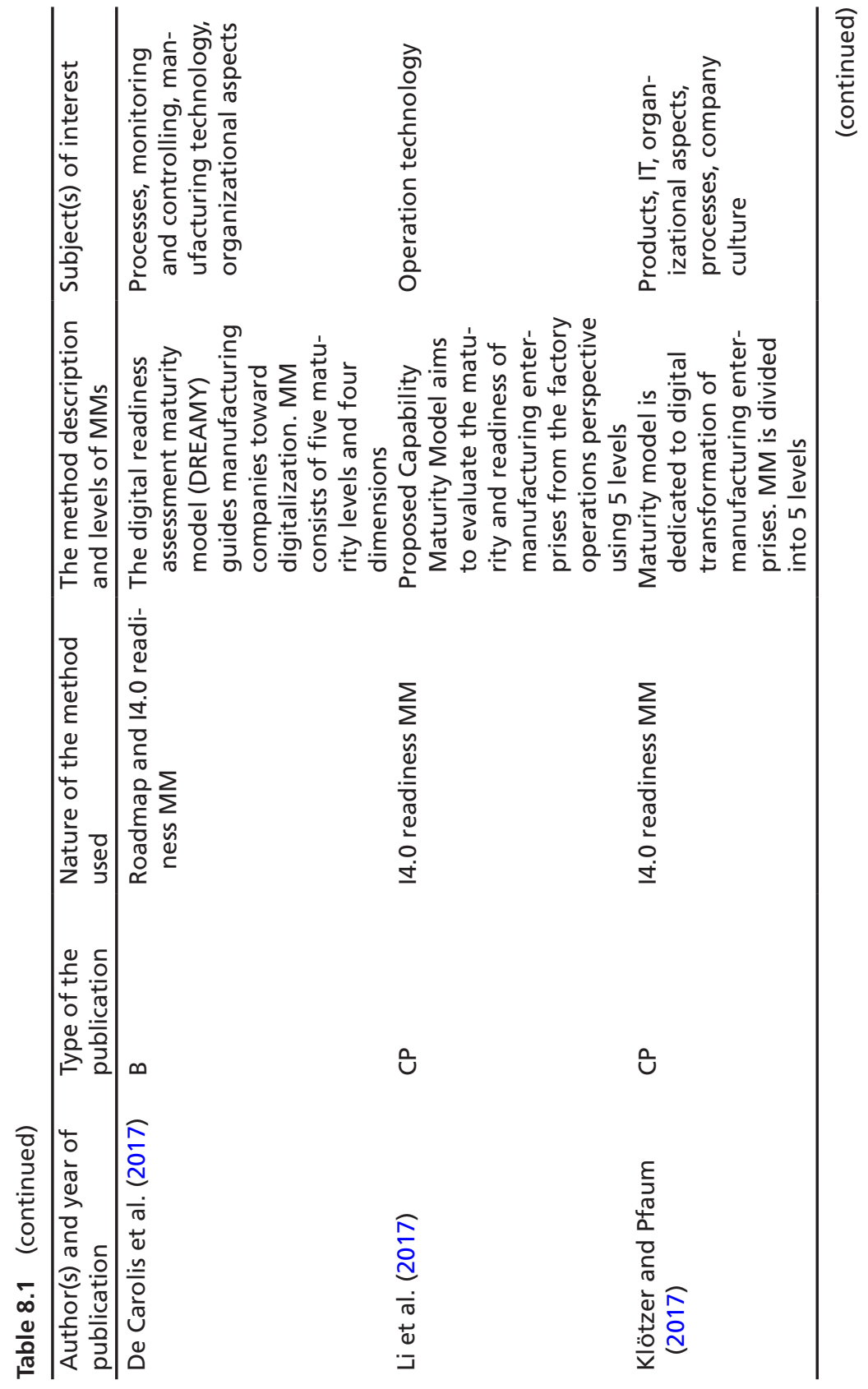




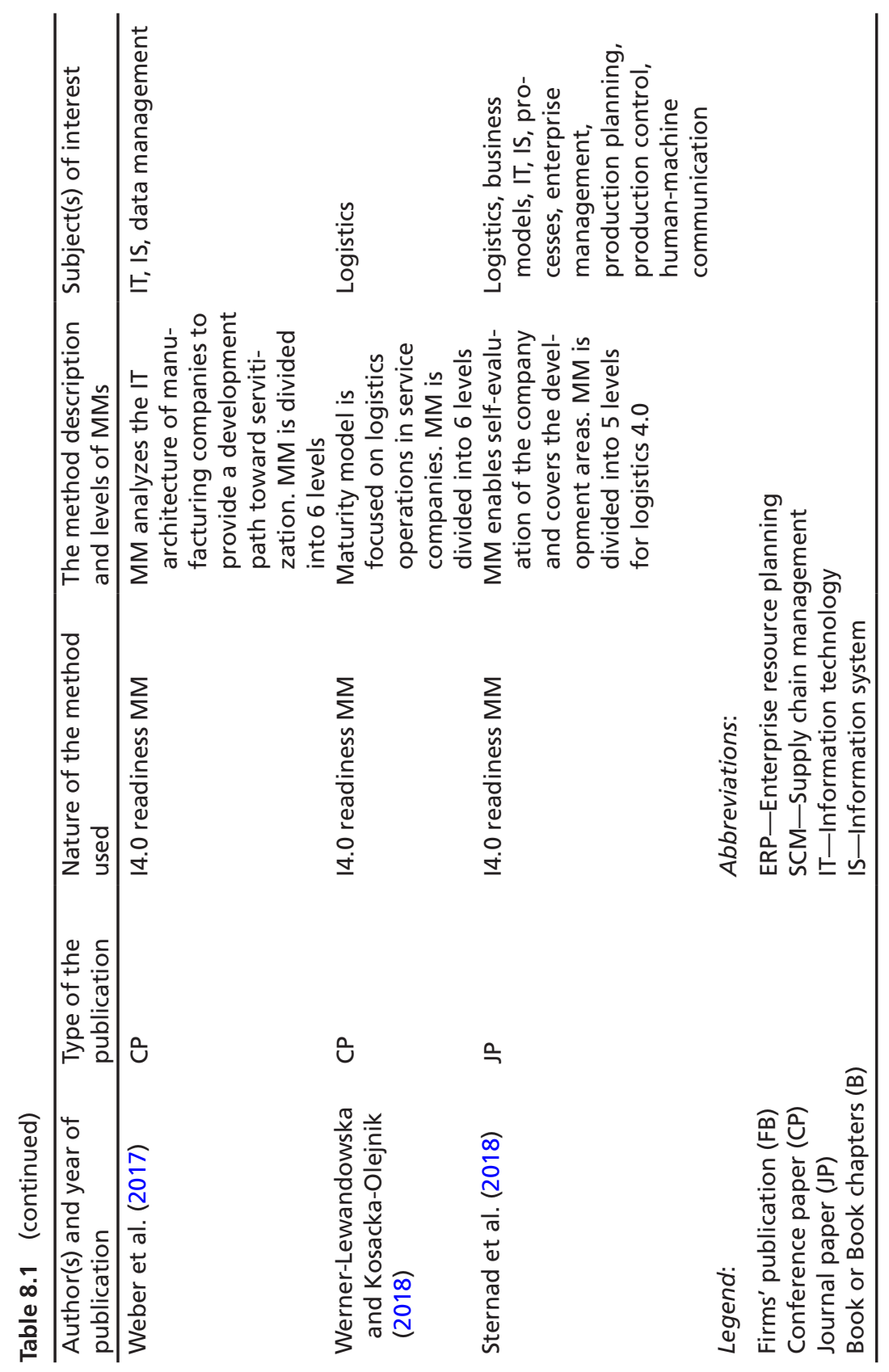




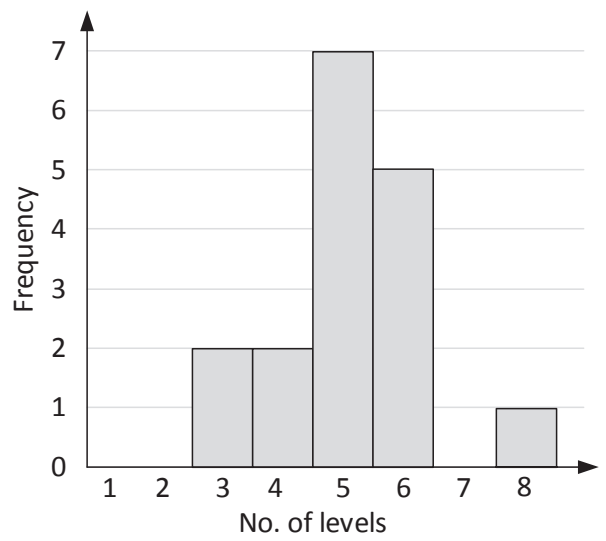

Fig. 8.1 Frequency distribution of the progress levels used in the reviewed MMs

of 15 references, and the nonacademic literature is represented by 5 literature sources.

When analyzing levels of the examined I4.0 MMs, they vary from 3 to 8 stages. Frequency distribution of the levels used in the reviewed MMs is depicted in Fig. 8.1. As can be seen, the most commonly occurring number of levels in the MMs is 5 . This is in line, e.g., with the representative generic capability MM for software process program which also uses 5 stages of maturity progress (Paulk et al. 1993).

Our next interest was to learn which domains of MMs dominated in the investigated literature. For this purpose, the following diagram in Fig. 8.2 is provided.

As shown in Fig. 8.2, the domains of interest can be divided into two categories classified as "essential domains" and "recommended domains." Then, the domains with a frequency of 4-6 fall into the first category, and the rest of the subjects of interest belong to the second category.

\subsection{Problem Description}

As mentioned above, a great challenge for SMEs lies in the transfer of I4.0 expertise and technologies to their environment. Moreover, this challenge also includes transfer toward mass customization. Comparing 


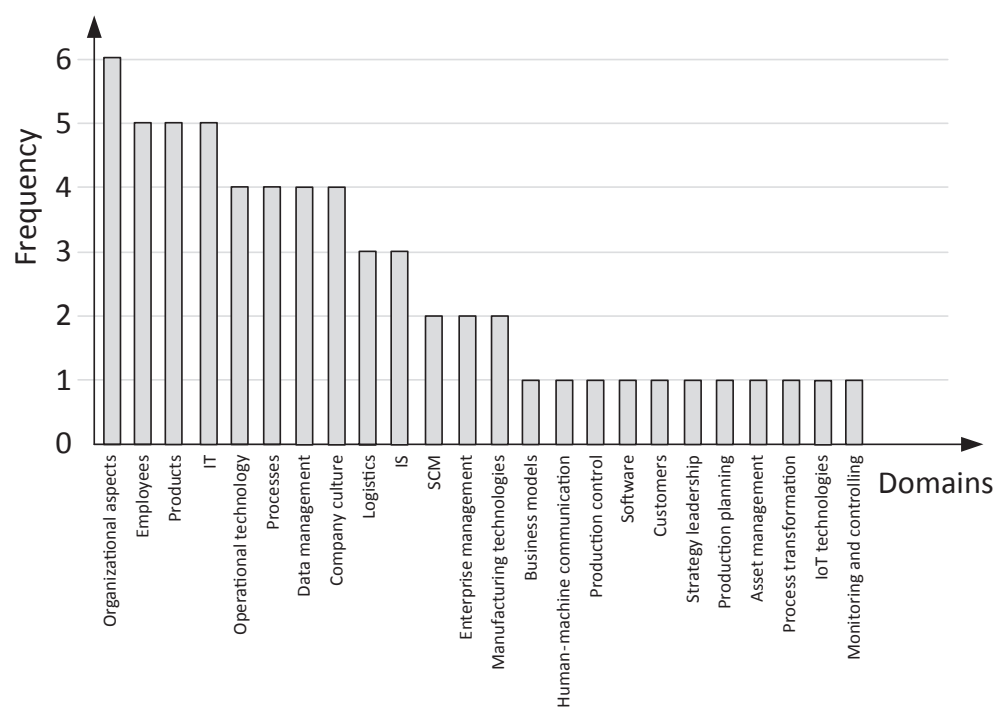

Fig. 8.2 Categorization of subjects of interest based on their appearance in the 14.0 MMs

starting conditions for introduction of the I4.0 concept between large companies and SMEs, it can be stated that larger companies can follow the higher maturity levels in the technological domain for this concept more quickly than SMEs. This is because they can invest more money, time, and expertise into this transfer. On the other hand, an advantage of SMEs against large companies is lower complexity of their business and manufacturing processes. And thus, organizational and cultural changes can be implemented into the whole enterprise much more easily.

Even though several I4.0 MMs which focused on organizational facets were identified in the aforementioned section, none of them can be considered as standardized or universal. Moreover, the described approaches in Table 8.1 were mostly based on self-assessment by using questionnaires which offered answers yes or no, and were oriented toward the identification of a company's current state related to the maturity requirements. Reflecting on the findings of the review from Sect. 8.2, the ambition of our research is to develop a comprehensive I4.0 MM focused on organizational and managerial aspects in terms of 
mass customization. The proposed I4.0 MM is based on a collaborative approach using a questionnaire method for self-assessment described further in Sects. 8.5.1 and 8.5.2. The outputs of this questionnaire maturity model (QMM) are dedicated to identifying status quo and mapping gaps which need to be filled in order to reach the planned state and are further used as inputs for the creation of the I4.0 readiness MM. Moreover, our approach includes the methodological recommendations in form, e.g., how to measure progress in product modularity and process modularity using quantitative indicators. In addition, we propose a generic organizational model of mass customized manufacturing as a condition for reaching an advanced stage (Level 4) of the proposed MM.

\subsection{Methodology}

The aim of this section is to guide you through the process of developing the managerial and organizational maturity models. This process starts with a structural analysis of the existing literature related to I4.0 MMs (Sect. 8.2). It helped us to identify what methods already exist, to understand the relationships between them, to find out which domains are essential for I4.0 introduction, and so on. Based on the obtained findings, it was easier to specify categories and levels of QMM for mapping of requirements of SMEs to meet higher maturity levels in the context of the strategy for Industry 4.0. The method used for this purpose is described in detail in Sect. 8.5.1. Subsequently, application of the QMM is presented in Sect. 8.5.2. Respondents were represented by 10 selected SMEs. The next step in our approach was aimed at specifying differences between current states and required states and identifying the key requirements of SMEs on the bases of the obtained results from the questionnaire. In order to validate the obtained results, the overall internal consistency of the questionnaire was measured by Cronbach's alpha coefficient (see Sect. 8.5.3). Development of the I4.0 readiness MM (I4.0 RMM) that is shown in Sect. 8.6, followed methodological recommendations from the relevant scientific publications dealt with in Sect. 8.2. Finally, based on empirical experiences, the 
generic organizational model of mass customized manufacturing was proposed (see Sect. 8.6.1). The whole methodological framework in the form of a step-by-step guide is available in Fig. 8.3.

\subsection{Proposed Approaches and Solutions}

This section will provide readers with substantial research outputs that are outlined in Fig. 8.3.

\subsubsection{Development of QMM}

The QMM method was selected with the aim of applying the collaborative approach by involvement of selected SMEs in order to identify their current status and define future targets in the context of I4.0 challenges. In order to map the requirements of SMEs to meet planned maturity levels in the context of the strategy I4.0, the categories of the QMM for investigation of the managerial and organizational model, were firstly defined. For this purpose, five categories were empirically selected in our previous work, which are business strategy, business models related to product, innovation culture, organizational production model, and knowledge management (Modrak et al. 2019). For each of the categories, five maturity levels were specified in descriptive form as shown in Appendix 8.1.

After the SMEs' self-assessment, obtained questionnaire outputs resulted in specification of their key requirement. The questionnaire form contained options scaled from the lowest level (L1) to the highest level (L5) as shown in Appendix 8.4.

The obtained results from the fulfilled questionnaire forms are presented in the next section and considered further in Sect. 8.5.3.

\subsubsection{Application of the QMM}

Results from the mapping of requirements using the QMM method to identify the current situation and future targets of the 10 companies are graphically depicted in Fig. 8.4. 
Section 8.2
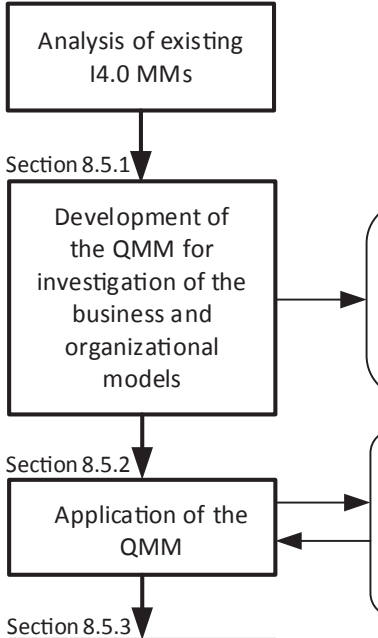

QMM for 5 categories

- Business strategy

- Business models related to product

- Innovation culture

- Organizational production model

- Knowledge management

Questionnaire results analysis in order to

identify the key

requirements of SMEs

SMES

Company no. 1

Company no. 2

:

Company no. 10

Section 8.6

Development of the

14.0 RMM focused on

organizational

capabilities for mass

customized

manufacturing

Section 8.6.2.2

Development of generic organizational

model of mass

customized

manufacturing

Fig. 8.3 Research methodological framework 

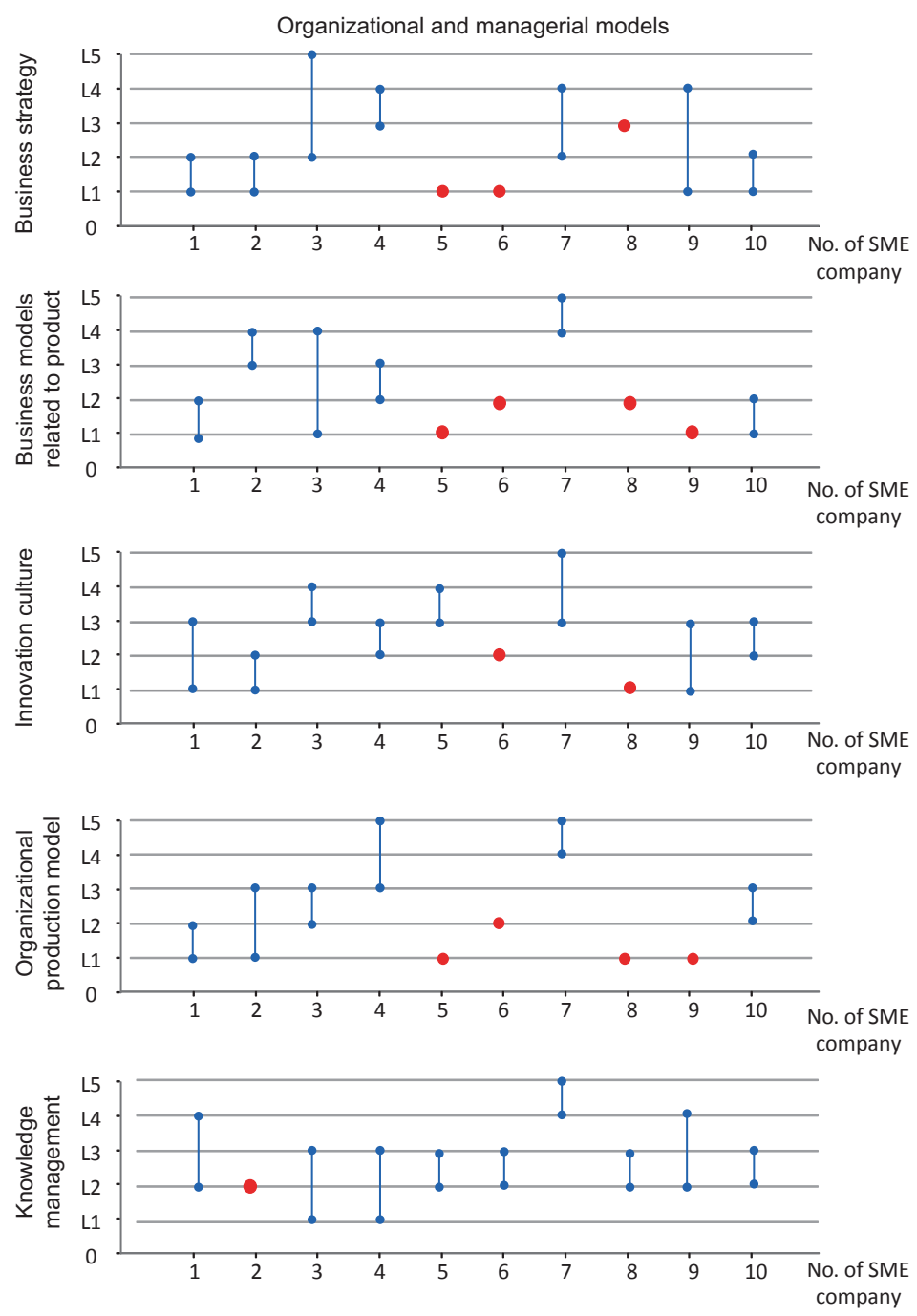

Legend: i - request to change from level target
- - level of current state without request for change

Fig. 8.4 Results from mapping of individual requirements 
According to the obtained results shown in Fig. 8.4, it is possible to start with their processing in order to identify the key requirement(s) of SMEs in line with given research objectives.

\subsubsection{Identification of the Key Requirement of SMEs}

In this step, questionnaire results were processed in the following way.

For determination of the order of significance of assessed categories, the weight coefficient $(V)$ was used:

$$
V=\sum_{i=1}^{10} R_{i} \cdot W_{i}
$$

where,

$R_{i}$ - the Rate of the change of $i$-th SME, while if the current state is the same as future target then $R_{i}$ equals 0 , and vice versa, $R_{i}$ equals 1 .

When $R_{i}=1$, then for each gap between current state and future target a Weighting value $(W)$ is assigned. The weighting value depends on the level of change.

When the extent of the gap equals: 1 , then $W_{i}=1.2$

$$
\begin{aligned}
& \text { 2, then } W_{i}=1.4 \\
& 3 \text {, then } W_{i}=1.6 \\
& \text { 4, then } W_{i}=1.8 \\
& \text { 5, then } W_{i}=2 .
\end{aligned}
$$

The order of categories of significance based on the result values of the coefficient $V$ calculated using Eq. (8.1) are as follows: Category No. 5 $(V=11.6)$; Category No. $3(V=10.2)$; Category No. $1 \quad(V=9.4)$; Category No. $2(V=7.6)$ and Category No. $4(V=7.6)$.

Then, identification of the key requirement(s) will be determined as follows:

Firstly, the Average level of the current state levels $\left(C L_{\mathrm{A}}\right)$ for each category is enumerated using the arithmetical mean from 10 values of the level numbers:

$$
C L_{A}=\frac{\sum_{i=1}^{10} L_{i}}{10} .
$$


Secondly, the Average level of the future target levels $\left(R L_{A}\right)$ for each category is determined analogically:

$$
R L_{A}=\frac{\sum_{i=1}^{10} L_{i}}{10} .
$$

Finally, the average gap for each category is obtained as the difference between $R L_{A}$ and $C L_{A}$. The obtained average gaps are graphically shown in Fig. 8.5.

However, the overall internal consistency of the questionnaire has to be measured by Cronbach's alpha (Cortina 1993) to validate results from fulfilled questionnaires from the population sample represented by 10 SMEs $(S 1, S 2, \ldots, S 10)$. This chapter contains results from a questionnaire survey in the domain of business and organizational models,

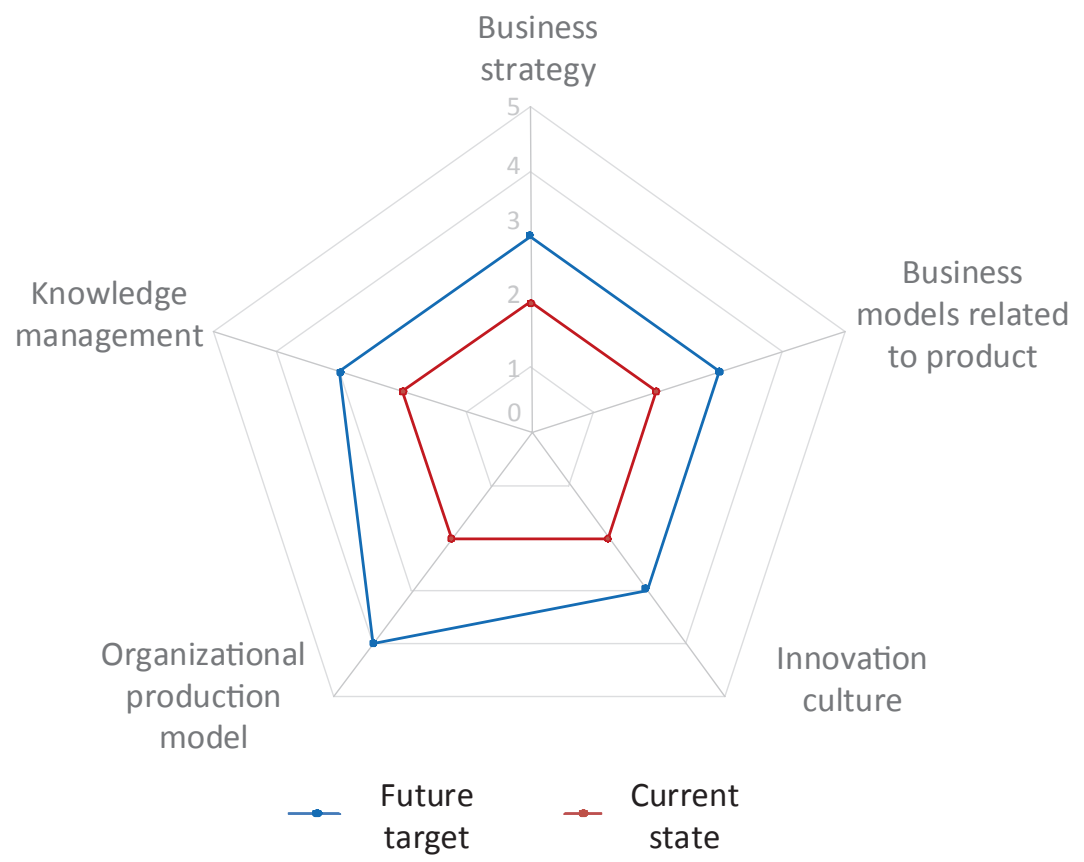

Fig. 8.5 Spider graph of differences between current states and future targets 
which was a part of the QMM used for the other two domains, i.e., smart logistics and smart manufacturing with a total number of 15 questions (see Appendices 8.2 and 8.3). Due to this fact, overall internal consistency of the questionnaire used in the QMM will be tested for all three domains. For this purpose, the obtained input data needed to calculate Cronbach's alpha coefficient were arranged into Table 8.2.

Subsequently, Cronbach's alpha coefficients were separately calculated for the current states and the future targets by using the formula (Machin et al. 2007):

$$
\alpha=\left(\frac{k}{(k-1)}\right) *\left(1-\left(\frac{\sum\left(s_{i}^{2}\right)}{s_{t}^{2}}\right)\right),
$$

where,

$k=$ number of items-questions in questionnaire $(Q)$,

$S_{i}=\mathrm{SD}$ of $i$ th item,

$S_{t}=\mathrm{SD}$ of sum score.

Table 8.2 Input data for calculations of Cronbach's alpha coefficients

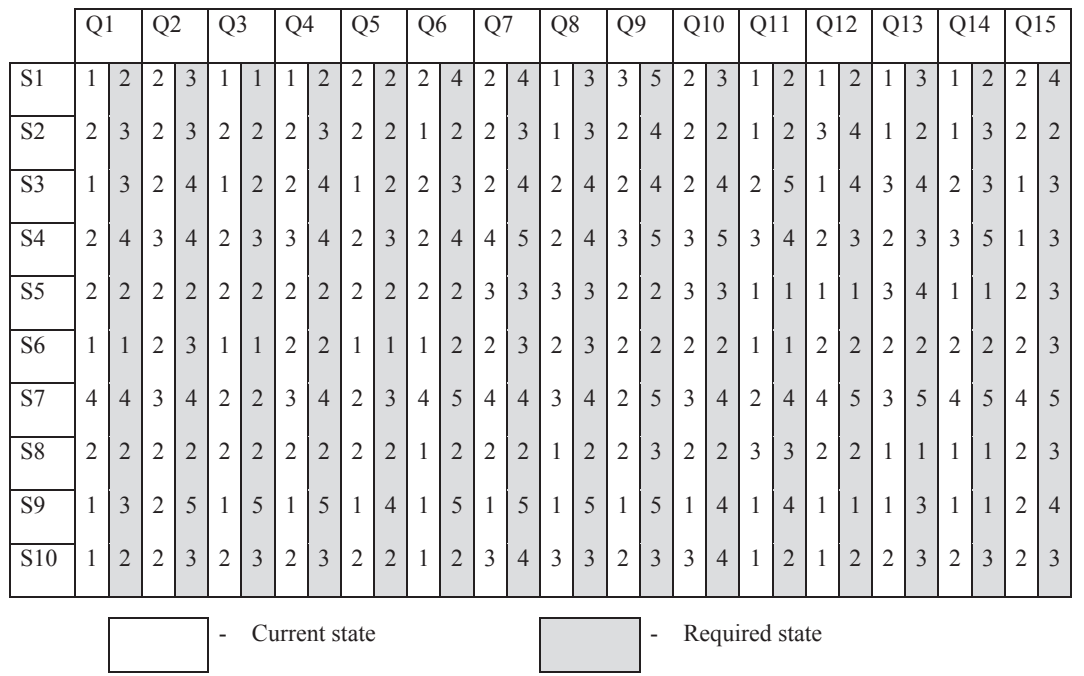


Then, Cronbach's alpha coefficient for the current states is 0.92 and the future targets equal 0.94. Based on a commonly accepted rule for describing internal consistency using Cronbach's alpha, in both cases, the internal consistencies are excellent.

According to the obtained results, the category titled "organizational production model" was specified by 10 SMEs as the key requirement (see Fig. 8.6) and for this key requirement will be further proposed an I4.0 readiness MM with an orientation toward organization capabilities for mass customized manufacturing.

\subsection{Maturity Model of Organizational Capabilities for Mass Customized Manufacturing}

In this Section, the I4.0 readiness MM is proposed including a recommended specification for SMEs as preconditions for successful implementation of mass customized manufacturing. Presented I4.0 RMM is divided into 5 stages: conventional, starting, moderate, advanced, and optimized, as depicted in Fig. 8.6. The structure of its characteristics can be divided into two groups.

The first one includes the main features of the stages such as: product standardization, product modularity, process modularity, integration of product configurator into process planning, and optimization of intelligent technologies and products. The main features of the first group can be formally modeled by using the arithmetic recursive formula:

$$
a_{n}=a_{n-1}+d
$$

where $n$ are integers $1-5$,

$$
a_{0}=0 \text {, }
$$

and $d$ is common difference (in our case "one step up").

Then, the 1st step up is represented by product standardization, and the 5th step up relates to optimization of intelligent technologies and products. 


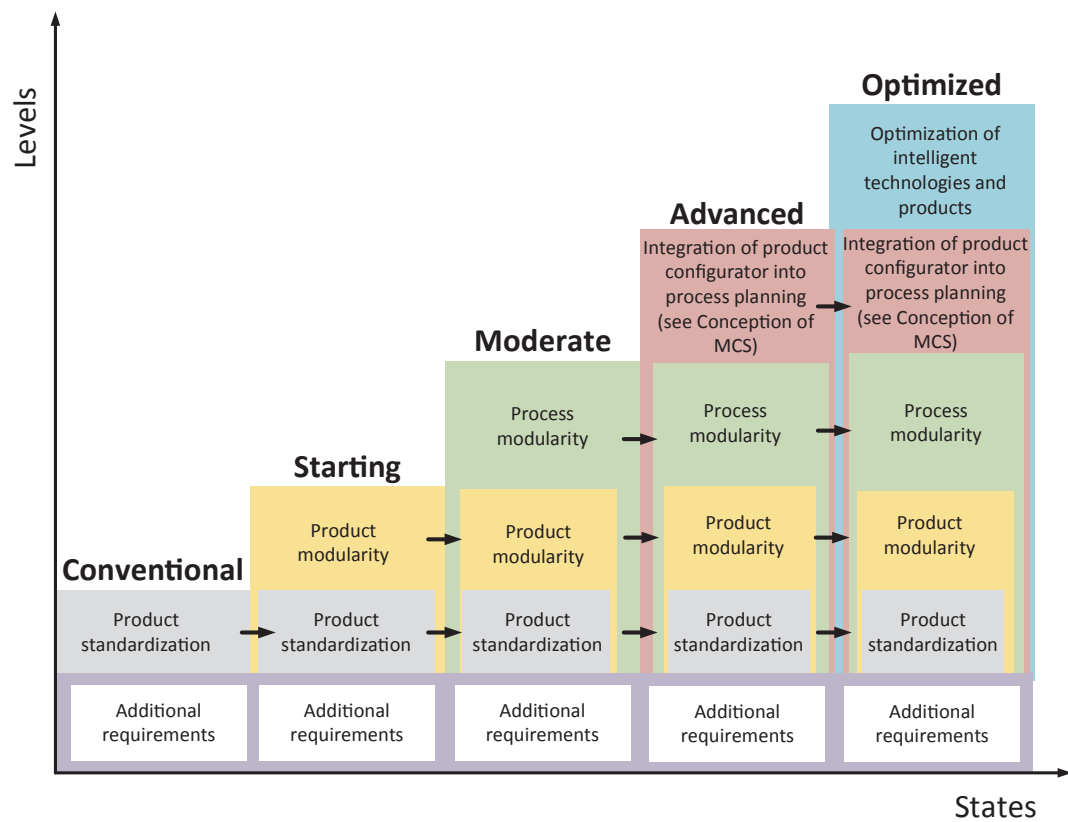

Fig. 8.6 I4.0 RMM of organizational capabilities for mass customized manufacturing

The second group consists of additional requirements that are described in Sect. 8.6.1. The list of additional requirements is only informative, and can be subject to variations.

\subsubsection{Additional Requirements of the Maturity Model}

The additional requirements of the I4.0 RMM might include at least the following characteristics.

At the Conventional stage:

- Traditional approach based on product standardization of particular products offered for different markets

- Common operational planning methods, communication with suppliers using basic ICT technology, manual processing of orders and logistics, no monitoring of logistics 
- Production not connected with ERP system through manufacturing execution systems (MES)

- Physical product without digital functions, sporadic combination of products and digital services.

At the Starting stage:

- Orientation of product modularization

- Assessment of suppliers coordinated with logistics and production, ERP system connected with production through MES

- Internally integrated system-based planning, optimization of logistics operations

- Data analysis for mass customized production needs

- Groups of standardized products are shipped to different markets according to local needs.

At the Moderate stage:

- Orientation on process modularization

- Integrated customer solutions across supply chain boundaries, collaboration with external logistics providers, transfer of product characteristics to the ERP system for marketing purposes

- Individualized customer approach and interaction with supply chain partners by using specific ICT technology

- IT integration with suppliers through ERP system

- Partial focus on the development of intelligent technologies and products.

At the Advanced stage:

- Using product configurators to enhance communication with clients who are ordering customized products

- Adaptation of organizational model of production for mass customized production

- Transition to one-piece flow production in order to increase effectiveness of manufacturing processes 
- Application of modern ICT and automatic identification technologies for monitoring and tracking of parts, components, modules, and final products in manufacturing plant and supply chains.

\section{At the Optimized stage:}

- Optimization of the organizational model of production for mass customized products

- Optimization of product modularity and process modularity by using quantitative metrics

- Communication with suppliers is completely digitalized, intensive optimization of warehouses, real-time transparency of supply chain

- Application of tools for digital marketing and sales

- Optimization of intelligent technologies and products.

\subsubsection{Description of the Main Features of the Maturity Model}

The first important features of preconditions of organizational capabilities for mass customized manufacturing that are indicated in our I4.0 readiness MM, are product standardization, product modularity, and process modularity. As is well-known, standardization of the internal components simplifies their assembly into many different products according to a customer's needs (George 2003). It can also be stated that modularity-based approaches in manufacturing practice such as product modularity and process modularity can improve mass customization capability and are strong enablers of this marketing and manufacturing strategy (Kotha 1995; Gilmore 1997). Accepting these statements is one thing, but when companies want to follow the steps shown in our I4.0 readiness MM, they need to manage improvements of these features. However, we also have to accept a common rule: if you can't measure it, you can't manage it. Therefore, it is recommended that effective quantitative measurement for this purpose is applied; this is described below. 


\subsubsection{Product Modularity and Process Modularity}

There are several approaches to measure product modularity, which are available in the literature. A comprehensive overview of them has been offered by Ulrich (1994). Hölttä-Otto and De Weck (2007) proposed a product modularity metric called the Singular Value Modularity Index (SMI) to quantify the degree of modularity of a product on its internal structure. SMI is theoretically bounded between 0 and 1, while SMI closer to 1 indicates a higher degree of modularity and vice versa. For its calculation, the following expression is used:

$$
\mathrm{SMI}=1-\frac{1}{N \cdot \sigma_{1}} \sum_{i=1}^{N-1} \sigma_{i}\left(\sigma_{i}-\sigma_{i+1}\right),
$$

where:

$N$-is the number of components of the system

$\sigma_{i}$-represents singular values, $i=1,2, \ldots, N$ ordered in decreasing magnitude.

The authors of this measurement approach provide in the above mention literature sources useful examples of how the SMI measure can be applied.

According to Calcagno (2002), not only is a product modularity measurement important, but it is also necessary to measure a degree of modularity of manufacturing systems. On the other hand, there is a dearth of process modularity measures, which could be simply applied for managerial purposes. For this reason, we proposed to adopt the SMI to measure the degree of modularity of manufacturing processes (Modrak and Soltysova 2018a).

Process modularity issues are important, particularly in the context of optional components entering into an assembly station with a human presence. As a consequence, such a station might be divided into two or more substations to minimize complexity of the operation in order to eliminate the tendency to make mistakes. The important precondition 
to applying SMI for process modularity is transformation of real process operations into models using graph theory. A methodological procedure of how to apply SMI to measure process modularity can be found in the mentioned literature.

\subsubsection{Integration of Product Configurator into Process Planning}

The proposed generic model of how to organize manufacturing and marketing activities in terms of mass customization is depicted in Fig. 8.7. The model can be divided into four systems, namely the product configuration system, product arrangement and process planning system, manufacturing system, and final product assembly system. The product life cycle in this segment starts in the configuration system, where the product is specified according to customer needs, and which consists of a product definition module. Outputs from this system are, at a minimum, characterized by article codes (ACs), quantity to be assembled $(\mathrm{Q})$, and production due dates (PDD). Moreover, functional requirements are also specified in this phase. When the final product is defined, component separation is performed according to a bill of material (BOM). Firstly, components are divided into stable (S), compulsory optional (CO) components, and voluntary optional (VO) components. This classification is important, especially at higher levels of the maturity model where variety-based complexity is a matter of major concern affecting the product and process design (Modrak and Soltysova 2018b). Requirements for the CO and VO components further face a make or buy decision, where they are divided into their own base production or ordered from a supplier. Subsequently, schedules for product manufacturing are generated. Then, based on information about component consolidation, detailed schedules for multi model assembly line(s) are calculated and provided to the product assembly system department. Finally, the product assembly process is triggered and managed. This phase mostly includes the performance of functional requirements. 


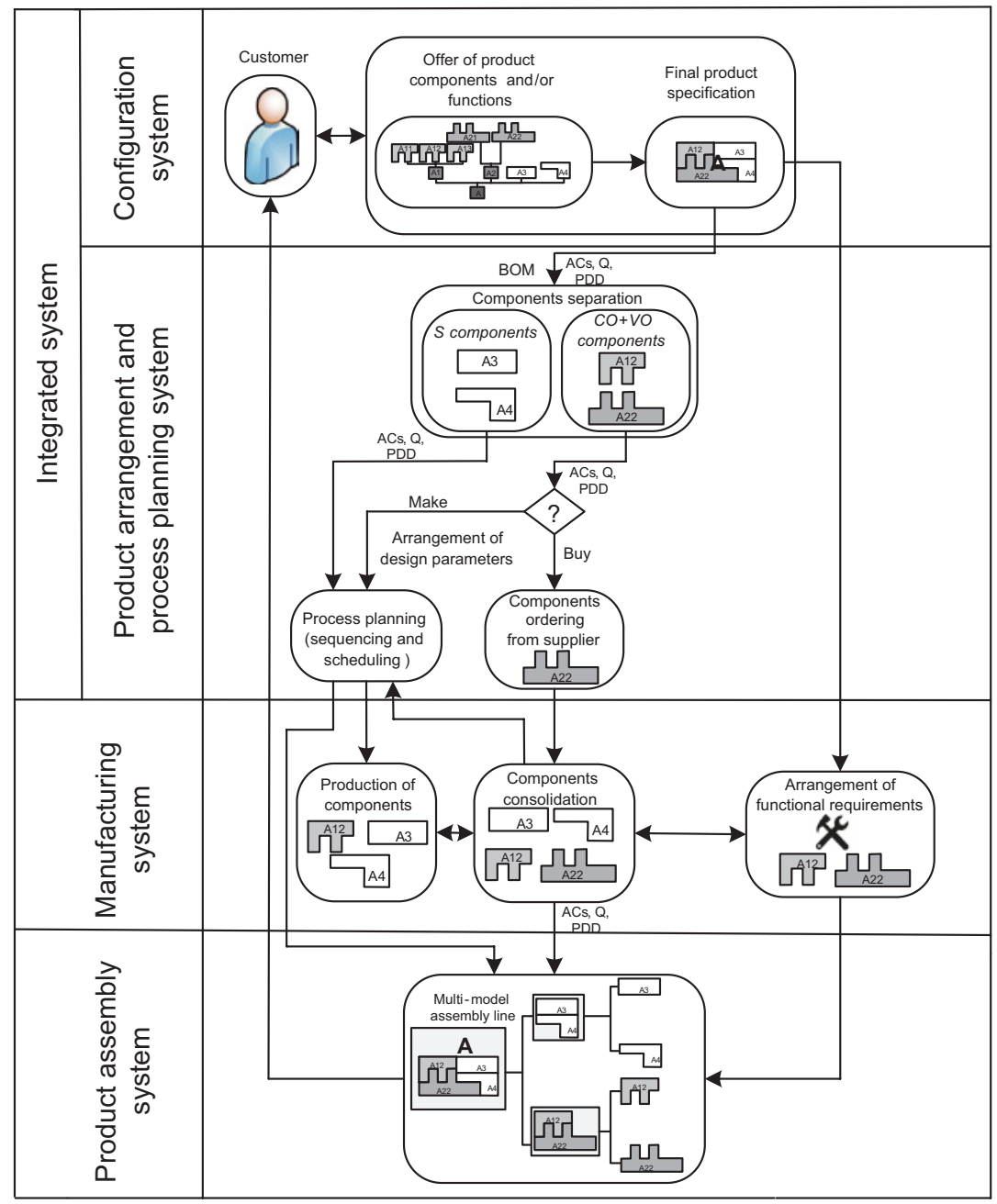

Fig. 8.7 Model of the relations between orders and manufacturing operations

\subsection{Future Research Work and Conclusions}

Analysis of the results obtained from the application of the QMM confirms and emphasizes that an effort of SMEs in the context of Industry 4.0 challenges has to also be dedicated to organizational and managerial 
aspects. For this purpose, theoretical concepts such as frameworks or maturity models can be useful to anticipate relevant directions and factors affecting the achievement of this strategic goal. Accordingly, and in line with this statement, this chapter offers a structured approach to carrying out self-assessment for Industry 4.0 implementation, and moreover, proposes the generic I4.0 RMM as the roadmap for helping companies to navigate them and understand their current state in the mass customization environment.

The literature review on existing approaches was mostly based on self-assessment by using a questionnaire with yes or no answers, and oriented towards the identification of a company's current state related to the maturity requirements. The proposed maturity models are focused on organizational and managerial aspects in terms of mass customization. While I4.0 QMM can be used for mapping the three domains: smart manufacturing, smart logistics, and organizational and managerial facets, the I4.0 RMM is dedicated to the readiness of organizational capabilities for mass customized manufacturing.

The given results will be used in our future work for the development of technical solutions and managerial methods that will enable managers to make better decisions for the digital transformation of SMEs from the current state to the targeted state. In this context, the generic conception of mass customized manufacturing based on the integration of a product configurator in process planning will be further developed. For example, it will be necessary to follow the development of marketing tools based on social networks and new communication channels. As is known, the connection of a product configurator with a Facebook site can facilitate not only social connections between existing and potential customers but also help in the codesign of activities (Gownder et al. 2011).

In spite of early skepticism about mass customization, which was seen as not very useful and as a contradictory concept, its penetration in different industries has become a reality. As was almost predicted, MC has become an imperative rather than a choice leading to sustainable success across business sectors (Piller 2010). However, wider acceptance of this strategy in individual industries will strongly depend on the availability of attainable digital manufacturing devices belonging to the smart manufacturing concept. 


\section{Appendix 8.1}

Maturity levels of QMM in the Organizational and managerial domain

\begin{tabular}{|c|c|c|}
\hline Category title & Level & Description of maturity level \\
\hline \multirow[t]{5}{*}{ Business strategy } & L1 & $\begin{array}{l}\text { The organization does not have a formal strategy } \\
14.0 \text { as a part of the corporate strategy }\end{array}$ \\
\hline & L2 & $\begin{array}{l}\text { Managers are convinced of the need to develop a } \\
\text { strategy for } 14.0\end{array}$ \\
\hline & L3 & $\begin{array}{l}\text { Managers work on a strategy for } 14.0 \text { focused on } \\
\text { technological aspects }\end{array}$ \\
\hline & L4 & $\begin{array}{l}\text { Business activities for technology change are } \\
\text { aligned with company strategy }\end{array}$ \\
\hline & L5 & $\begin{array}{l}\text { The strategy for } 14.0 \text { is more focused on people } \\
\text { than on production technology }\end{array}$ \\
\hline \multirow{5}{*}{$\begin{array}{l}\text { Business mod- } \\
\text { els related to } \\
\text { product }\end{array}$} & L1 & $\begin{array}{l}\text { Earning income from the sale of standardized } \\
\text { products }\end{array}$ \\
\hline & L2 & $\begin{array}{l}\text { Groups of standardized products are shipped to dif- } \\
\text { ferent markets according to local needs }\end{array}$ \\
\hline & L3 & $\begin{array}{l}\text { Possibility to customize the product based on } \\
\text { group(s) of variant modules }\end{array}$ \\
\hline & L4 & $\begin{array}{l}\text { Possibility to customize the product from a wide } \\
\text { range of components }\end{array}$ \\
\hline & L5 & Mass personalization \\
\hline \multirow{5}{*}{$\begin{array}{l}\text { Innovative } \\
\text { culture }\end{array}$} & L1 & Openness for digital technologies \\
\hline & L2 & $\begin{array}{l}\text { Identification with the building of digital } \\
\text { enterprise }\end{array}$ \\
\hline & L3 & $\begin{array}{l}\text { Orientation in the development of intelligent tech- } \\
\text { nologies and products }\end{array}$ \\
\hline & L4 & $\begin{array}{l}\text { Intelligent technologies and/or products are } \\
\text { introduced }\end{array}$ \\
\hline & L5 & $\begin{array}{l}\text { Optimization of intelligent technologies and } \\
\text { products }\end{array}$ \\
\hline \multirow{5}{*}{$\begin{array}{l}\text { Organizational } \\
\text { production } \\
\text { model }\end{array}$} & L1 & Traditional approach by type of production type \\
\hline & L2 & Orientation on product modularization \\
\hline & L3 & Orientation on process modularization \\
\hline & L4 & $\begin{array}{l}\text { Application of the organizational model of produc- } \\
\text { tion for mass customized products }\end{array}$ \\
\hline & L5 & $\begin{array}{l}\text { Optimization of the organizational production } \\
\text { model for mass customization }\end{array}$ \\
\hline
\end{tabular}




\begin{tabular}{lll}
\hline Category title & Level & Description of maturity level \\
\hline $\begin{array}{l}\text { Knowledge } \\
\text { management }\end{array}$ & L1 & $\begin{array}{l}\text { The organization does not have any formal knowl- } \\
\text { edge management strategy (KM) } \\
\text { Managers are aware of the need to develop their } \\
\text { own strategy KM } \\
\text { Managers develop and implement the KM strategy } \\
\text { Activities for creation and sharing of knowledge } \\
\text { are in line with the KM strategy focused on tech- } \\
\text { nology and people } \\
\text { Activities for creating and sharing knowledge are } \\
\text { more people-oriented than on technology. The } \\
\text { sustainability of the established KM is perma- } \\
\text { nently monitored }\end{array}$ \\
L5 & L5 & \\
& &
\end{tabular}

\section{Appendix 8.2}

Maturity levels of QMM in the Smart logistics domain

\begin{tabular}{|c|c|c|}
\hline Category title & Level & Description of maturity level \\
\hline \multirow{5}{*}{$\begin{array}{c}\text { Transport } \\
\text { logistics }\end{array}$} & L1 & Decentralized managed transport \\
\hline & L2 & Centralized managed transport \\
\hline & L3 & $\begin{array}{l}\text { Predictive centralized transport. Ad hoc managed } \\
\text { distribution }\end{array}$ \\
\hline & L4 & $\begin{array}{l}\text { Predictive centralized transport. Optimized manage- } \\
\text { ment of distribution }\end{array}$ \\
\hline & L5 & Use of autonomous vehicles \\
\hline \multirow[t]{5}{*}{$\begin{array}{l}\text { Outbound } \\
\text { logistics }\end{array}$} & L1 & $\begin{array}{l}\text { Push management of the delivery process (in } \\
\text { warehouses) }\end{array}$ \\
\hline & L2 & Order-based delivery process control \\
\hline & L3 & $\begin{array}{l}\text { Order-based delivery process control with sales } \\
\text { monitoring }\end{array}$ \\
\hline & L4 & Automatic control of the delivery process \\
\hline & L5 & $\begin{array}{l}\text { Automatic delivery process management with } \\
\text { prediction of future order }\end{array}$ \\
\hline \multirow{5}{*}{$\begin{array}{l}\text { In-house } \\
\text { logistics }\end{array}$} & L1 & Use of manual means in inter-operational traffic \\
\hline & L2 & $\begin{array}{l}\text { Use of manually operated trolleys in inter-operational } \\
\text { traffic }\end{array}$ \\
\hline & L3 & $\begin{array}{l}\text { Use of automatically guided trolleys in inter-operational } \\
\text { traffic on defined routes }\end{array}$ \\
\hline & L4 & $\begin{array}{l}\text { Use of automatically guided trolleys in inter-operational } \\
\text { traffic on open production area }\end{array}$ \\
\hline & L5 & $\begin{array}{l}\text { Management of autonomous trolleys through } \\
\text { production facilities }\end{array}$ \\
\hline
\end{tabular}




\begin{tabular}{|c|c|c|}
\hline Category title & Level & Description of maturity level \\
\hline \multirow{5}{*}{$\begin{array}{l}\text { Inbound } \\
\text { logistics }\end{array}$} & L1 & Push management of the supply process (in warehouses) \\
\hline & $\mathrm{L} 2$ & Pull method for managing the supply process (JIT) \\
\hline & L3 & $\begin{array}{l}\text { Pull method fot managing the supply process (JIT) pro- } \\
\text { vided by the retailer }\end{array}$ \\
\hline & L4 & Autonomous inventory management \\
\hline & L5 & Predictive inventory management \\
\hline \multirow{5}{*}{$\begin{array}{l}\text { Warehouse } \\
\text { management }\end{array}$} & L1 & Use of manual devices for storage operations \\
\hline & L2 & Use of manually guided forklifts \\
\hline & L3 & $\begin{array}{l}\text { Use of automated guided vehicle systems and auto- } \\
\text { mated storage systems }\end{array}$ \\
\hline & L4 & $\begin{array}{l}\text { Use of automatic systems with links to superior enter- } \\
\text { prise management systems }\end{array}$ \\
\hline & L5 & $\begin{array}{l}\text { Use of automatic and/or collaborative transport and } \\
\text { storage trolleys }\end{array}$ \\
\hline
\end{tabular}

\section{Appendix 8.3}

Maturity levels of QMM in the Smart production domain

\begin{tabular}{lll}
\hline Category title & Level & Description of maturity level \\
\hline Data processing in the production & L1 & $\begin{array}{c}\text { Conventional data processing } \\
\text { methods (waybills, etc.) }\end{array}$ \\
Use of optical technologies for \\
data processing (bar codes, etc.) \\
Use of radio frequency technolo- \\
gies for data processing (RFID)
\end{tabular}




\begin{tabular}{|c|c|c|}
\hline Category title & Level & Description of maturity level \\
\hline \multirow[t]{5}{*}{$\begin{array}{l}\text { Machine to machine } \\
\text { communication }\end{array}$} & L1 & $\begin{array}{l}\text { No exchange of information } \\
\text { between machines }\end{array}$ \\
\hline & L2 & Connect devices using a bus \\
\hline & L3 & $\begin{array}{l}\text { Machines have an industrial } \\
\text { Ethernet interface (local com- } \\
\text { puter network) }\end{array}$ \\
\hline & L4 & Machines have internet access. \\
\hline & L5 & $\begin{array}{l}\text { Web interfaces and information } \\
\text { exchange applications (M2M } \\
\text { software) }\end{array}$ \\
\hline \multirow[t]{5}{*}{$\begin{array}{l}\text { ICT infrastructures in the } \\
\text { production }\end{array}$} & L1 & $\begin{array}{l}\text { Exchange information via email/ } \\
\text { phone }\end{array}$ \\
\hline & L2 & Central data servers in production \\
\hline & L3 & Internet portals for data sharing \\
\hline & L4 & $\begin{array}{l}\text { Use of ICT to identify statuses in } \\
\text { production (e.g., status of order) }\end{array}$ \\
\hline & L5 & $\begin{array}{l}\text { Suppliers and/ or customers have } \\
\text { access to a web-supported IS } \\
\text { (MES) }\end{array}$ \\
\hline \multirow[t]{5}{*}{ Digitalization } & L1 & Basic level of digitization \\
\hline & L2 & Uniform digitization (horizontal) \\
\hline & L3 & $\begin{array}{l}\text { Horizontal and vertical } \\
\text { digitization }\end{array}$ \\
\hline & L4 & Full digitalization \\
\hline & L5 & Optimized full digitalization \\
\hline
\end{tabular}

\section{Appendix 8.4}

The questionnaire structure

\begin{tabular}{llll}
\hline No. of category & Category title & Current state & Future target \\
\hline 1 & Business strategy & L1 $\square$ & L1 $\square$ \\
& & L2 $\square$ & L2 $\square$ \\
& & L3 $\square$ & L3 $\square$ \\
& & L4 $\square$ & L4 $\square$ \\
2 & L5 $\square$ & L5 $\square$ \\
& Business models related to & L1 $\square$ & L1 $\square$ \\
& product & L2 $\square$ & L2 $\square$ \\
& & L3 $\square$ & L3 $\square$ \\
& & L4 $\square$ & L4 $\square$ \\
& & L5 $\square$ & L5 $\square$ \\
\hline
\end{tabular}




\begin{tabular}{|c|c|c|c|}
\hline No. of category & Category title & Current state & Future target \\
\hline \multirow[t]{5}{*}{3} & Innovative culture & L1 $\square$ & L1 $\square$ \\
\hline & & L2 $\square$ & L2 $\square$ \\
\hline & & L3 $\square$ & L3 $\square$ \\
\hline & & L4 $\square$ & L4 \\
\hline & & L5 $\square$ & L5 $\square$ \\
\hline \multirow[t]{5}{*}{4} & Organizational production & L1 $\square$ & L1 $\square$ \\
\hline & model & $\mathrm{L} 2 \square$ & $\mathrm{L} 2 \square$ \\
\hline & & L3 $\square$ & L3 $\square$ \\
\hline & & L4 $\square$ & L4 $\square$ \\
\hline & & L5 $\square$ & L5 $\square$ \\
\hline \multirow[t]{5}{*}{5} & Knowledge management & L1 $\square$ & L1 $\square$ \\
\hline & & L2 $\square$ & L2 $\square$ \\
\hline & & L3 $\square$ & L3 $\square$ \\
\hline & & L4 $\square$ & L4 $\square$ \\
\hline & & L5 $\square$ & L5 $\square$ \\
\hline
\end{tabular}

\section{References}

Ahuett-Garza, H., and T. Kurfess. 2018. A Brief Discussion on the Trends of Habilitating Technologies for Industry 4.0 and Smart Manufacturing. Manufacturing Letters 15: 60-63. https://doi.org/10.1016/j.mfglet.2018. 02.011 .

Avram, M., C. Bucsan, and T.C. Apostolescu. 2017. Specialised Sensorial Block. In MATEC Web of Conferences, vol. 121, 8002. EDP Sciences. https://doi.org/10.1051/matecconf/201712108002.

Barata, J., and P.R. Cunha. 2017. Climbing the Maturity Ladder in Industry 4.0: A Framework for Diagnosis and Action That Combines National and Sectorial Strategies. In Twenty-Third Americas Conference on Information Systems, Boston. Becker, J., R. Knackstedt, and J. Pöppelbuß. 2009. Developing Maturity Models for IT Management. Business \& Information Systems Engineering 1 (3): 213-222. https://doi.org/10.1007/s12599-009-0044-5.

Belforte, G., and G. Eula. 2012. Smart Pneutronic Equipments and Systems for Mechatronic Applications. Journal of Control Engineering and Applied Informatics 14 (4): 70-79.

Bitkom, V., V. Vdma, and V. Zvei. 2016. Implementation Strategy Industrie 4.0. Berlin, Germany. 
Brunoe, T.D., and K. Nielsen. 2016. Complexity Management in Mass Customization SMEs. Procedia CIRP 51: 38-43. https://doi.org/10.1016/j. procir.2016.05.099.

Calcagno, M. 2002, May. Dynamics of Modularity: A Critical Approach. In Euram Conference, 9 (11).

Chromjakova, F. 2016. Flexible Man-Man Motivation Performance Management System for Industry 4.0. International Journal of Management Excellence 7 (2): 829-840. https://doi.org/10.17722/ijme.v7i2.269.

Cortina, J.M. 1993. What Is Coefficient Alpha? An Examination of Theory and Applications. Journal of Applied Psychology 78 (1): 98. https://doi. org/10.1037/0021-9010.78.1.98.

Cotteleer, M., and B. Sniderman. 2017. Forces of Change: Industry 4.0. London: Deloitte Insights. https://doi.org/10.1016/j.compind.2017.04.002. Curtis, B., W.E. Hefley, and S.A. Miller. 2001. People Capability Maturity Model Version 2.0. Pittsburgh: Carnegie Mellon Software Engineering Institute 1 (104): 240-266.

De Carolis, A., M. Macchi, E. Negri, and S. Terzi. 2017, September. A Maturity Model for Assessing the Digital Readiness of Manufacturing Companies. In IFIP International Conference on Advances in Production Management Systems, 13-20. Cham: Springer. https://doi.org/10.1007/978-3-319-66923-6_2s.

Fang, C., X. Liu, P.M. Pardalos, and J. Pei. 2016. Optimization for a Three-Stage Production System in the Internet of Things: Procurement, Production and Product Recovery, and Acquisition. The International Journal of Advanced Manufacturing Technology 83 (5-8): 689-710. https://doi.org/10.1007/s00170-015-7593-1.

Fraser, P., J. Moultrie, and M. Gregory. 2002. The Use of Maturity Models/ Grids as a Tool in Assessing Product Development Capability. IEEE International Engineering Management Conference. https://doi.org/10.1109/ IEMC.2002.1038431.

Ganzarain, J., and N. Errasti. 2016. Three Stage Maturity Model in SME's Toward Industry 4.0. Journal of Industrial Engineering and Management (JIEM) 9 (5): 1119-1128. https://doi.org/10.3926/jiem.2073.

Geissbauer, R., J. Vedso, and S. Schrauf. 2016. Industry 4.0: Building the Digital Enterprise. PwC. https:/www.pwc.com/gx/en/industries/ industries-4.0/landing-page/industry-4.0-building-your-digital-enterprise-april-2016.Pdf.

George, M. 2003. Lean Six Sigma for Service, Chapter 1-The ROI of Lean Six Sigma for Services. New York: McGraw Hill Professional. 
Gilmore, J.H. 1997. The Four Faces of Mass Customization. Harvard Business Review 75 (1): 91-101.

Gökalp, E., U. Şener, and P.E. Eren. 2017. Development of an Assessment Model for Industry 4.0: Industry 4.0-MM. In International Conference on Software Process Improvement and Capability Determination, 128-142. Cham: Springer. https://doi.org/10.1007/978-3-319-67383-7_10.

Gownder, J.P., S. Rotman Epps, A.E. Corbett, C.A. Doty, T. Schadler, and J.L. McQuivey. 2011. Mass Customization Is (Finally) the Future of Products. Forrester Report. https://doi.org/10.1108/09544789910246615.

Hofmann, E., and M. Rüsch. 2017. Industry 4.0 and the Current Status as Well as Future Prospects on Logistics. Computers in Industry 89: 23-34. https://doi.org/10.1016/j.compind.2017.04.002.

Hölttä-Otto, K., and O. De Weck. 2007. Degree of Modularity in Engineering Systems and Products with Technical and Business Constraints. Concurrent Engineering 15 (2): 113-126. https://doi.org/10.1177/10632 93X07078931.

Jæger, B., and L.L. Halse. 2017. The IoT Technological Maturity Assessment Scorecard: A Case Study of Norwegian Manufacturing Companies. In IFIP International Conference on Advances in Production Management Systems, 143-150. Cham: Springer. https://doi.org/10.1007/978-3-319-66923-6_17. Kagermann, H., W. Wahlster, and J. Helbig. 2013. Umsetzungsempfehlungen für das Zukunftsprojekt Industrie 4.0. In Abschlussbericht des Arbeitskreises Industrie 4 (5). Frankfurt: Forschungsunion.

Katsma, C., H. Moonen, and J. van Hillegersberg. 2011. Supply Chain Systems Maturing Towards the Internet-of-Things: A Framework. In 24th Bled eConference eFuture: Creating Solutions for the Individual, Organisations and Society Proceedings, 478-494.

Kese, D., and S. Terstegen. 2017. Industrie 4.0-Reifegradmodelle. Institut für angewandte Arbeitswissenschaft. https://www.arbeitswissenschaft.net/ uploads/tx_news/Tool_I40_Reifegradmodelle.pdf, Accessed on May 25, 2018.

Klötzer, C., and A. Pflaum. 2017. Toward the Development of a Maturity Model for Digitalization Within the Manufacturing Industry's Supply Chain. In 2017 50th Hawaii International Conference on System Sciences, 4210-4219. https://doi.org/10.24251/hicss.2017.509.

Kotha, S. 1995. Mass Customization: Implementing the Emerging Paradigm for Competitive Advantage. Strategic Management Journal 16 (S1): 21-42. https://doi.org/10.1002/smj.4250160916. 
Kumar, Ravi, and Enose Nampuraja. 2018. Making Industry 4.0 RealUsing the Acatech I 4.0 Maturity Index. A Systematic Methodology for Manufacturing Enterprises to Assess Current Readiness and Strategize Their Industry 4.0 Journey. Infosys.

Leyh, C., K. Bley, T. Schäffer, and S. Forstenhäusler. 2016. SIMMI 4.0-A Maturity Model for Classifying the Enterprise-Wide It and Software Landscape Focusing on INDUSTRY 4.0. In 2016 Federated Conference on Computer Science and Information Systems (FedCSIS), 1297-1302. https:// doi.org/10.15439/2016F478.

Leyh, C., T. Sch, K. Bley, and S. Forstenh. 2017. Information Technology for Management. New Ideas and Real Solutions 277: 103-119. https://doi. org/10.1007/978-3-319-53076-5.

Li, Q., M. Brundage, D. Brandl, and S. Do Noh. 2017. Improvement Strategies for Manufacturers Using the MESA MOM Capability Maturity Model. In IFIP International Conference on Advances in Production Management Systems, 21-29. Cham: Springer. https://doi.org/10.1007/978-3-319-66923-6_3.

Lichtblau, K., V. Stich, R. Bertenrath, M. Blum, M. Bleider, A. Millack, K. Schmitt, E. Schmitz, and M. Schröter. 2015. IMPULS-Industrie 4.0-Readiness. Impuls-Stiftung des VDMA, Aachen-Köln.

Machin, D., M.J. Campbell, and S.J. Walters. 2007. Reliability and Method Comparison Studies. In Medical Statistics, 203-212.

Mettler, T. 2011. Maturity Assessment Models: A Design Science Research Approach. International Journal of Society Systems Science 3 (1/2): 213-222. https://doi.org/10.1504/IJSSS.2011.038934.

Modrak, V., eds. 2017. Mass Customized Manufacturing: Theoretical Concepts and Practical Approaches. CRC Press. https://doi.org/10.1201/9781315398983.

Modrak, V., and Z. Soltysova. 2018a. Axiomatic Design Based Complexity Measures to Assess Product and Process Structures. In MATEC Web of Conferences, 223. EDP Sciences. https://doi.org/10.1051/matecconf/201822301019.

Modrak, V., and Z. Soltysova. 2018b. Process modularity of Mass Customized Manufacturing Systems: Principles, Measures and Assessment. Procedia CIRP 67: 36-40. https://doi.org/10.1016/j.procir.2017.12.172.

Modrak, V., Z. Soltysova, and R. Poklemba. 2019. Mapping Requirements and Roadmap Definition for Introducing I 4.0 in SME Environment. In Advances in Manufacturing Engineering and Materials, 183-194. Cham: Springer. https://doi.org/10.1007/978-3-319-99353-9_20.

Paulk, M.C., B. Curtis, M.B. Chrissis, and C.V. Weber. 1993. Capability Maturity Model for Software. Version 1.1. Software Engineering Institute. https://doi.org/10.1109/52.219617. 
Pessl, E., S.R. Sorko, and B. Mayer. 2017. Roadmap Industry 4.0-Implementation Guideline for Enterprises. International Journal of Science, Technology and Society 5: 193-202. https://doi.org/10.11648/j.ijsts.20170506.14.

Piller, F.T. 2010. Handbook of Research in Mass Customization and Personalization, 1. World Scientific. https://doi.org/10.1142/p7378.

Rauch, E., D.T. Matt, C.A. Brown, W. Towner, A. Vickery, and S. Santiteerakul. 2018. Transfer of Industry 4.0 to Small and Medium Sized Enterprises. Advances in Transdisciplinary Engineering 7: 63-71. https://doi.org/10.3233/ 978-1-61499-898-3-63.

Rockwell Automation. 2014. The Connected Enterprise Maturity Model. Rockwell Automation, 12, USA.

Schumacher, A., S. Erol, and W. Sihn. 2016. A Maturity Model for Assessing Industry 4.0 Readiness and Maturity of Manufacturing Enterprises. Procedia CIRP 52: 161-166. https://doi.org/10.1016/j.procir.2016.07.040.

Singh, P.M., M. van Sinderen, and R. Wieringa. 2017. Smart Logistics: An Enterprise Architecture Perspective. CAiSE-Forum-DC, 9-16.

Sommer, L. 2015. Industrial Revolution-Industry 4.0: Are German Manufacturing SMEs the First Victims of This Revolution? Journal of Industrial Engineering and Management 8 (5): 1512-1532. https://doi.org/ 10.3926/jiem.1470.

Sternad, M., T. Lerher, and B. Gajsek. 2018. Maturity Levels for Logistics 4.0 Based on Nrw'S Industry 4.0 Maturity Model. Business Logistics in Modern Management 18: 695-708.

Tavana, M., eds. 2012. Decision Making Theories and Practices from Analysis to Strategy: IGI Global. https://doi.org/10.4018/978-1-4666-1589-2.

Ulrich, K. 1994. Fundamentals of Product Modularity. In Management of Design, 219-231: Dordrecht: Springer. https://doi.org/10.1007/978-94-0111390-8_12.

Weber, C., J. Königsberger, L. Kassner, and B. Mitschang. 2017. M2DDM-A Maturity Model for Data-Driven Manufacturing. Procedia CIRP 63: 173-178. https://doi.org/10.1016/j.procir.2017.03.309.

Werner-Lewandowska, K., and M. Kosacka-Olejnik. 2018. Logistics Maturity Model for Service Company-Theoretical Background. Procedia Manufacturing 17: 791-802. https://doi.org/10.1016/j.promfg.2018.10.130. Wong, B.K., and J.A. Monaco. 1995. Expert System Applications in Business: A Review and Analysis of the Literature: (1977-1993). Information \& Management 29 (3): 141-152. https://doi.org/10.1016/0378-7206(95)00023-P. 
Open Access This chapter is licensed under the terms of the Creative Commons Attribution 4.0 International License (http://creativecommons. org/licenses/by/4.0/), which permits use, sharing, adaptation, distribution and reproduction in any medium or format, as long as you give appropriate credit to the original author(s) and the source, provide a link to the Creative Commons license and indicate if changes were made.

The images or other third party material in this chapter are included in the chapter's Creative Commons license, unless indicated otherwise in a credit line to the material. If material is not included in the chapter's Creative Commons license and your intended use is not permitted by statutory regulation or exceeds the permitted use, you will need to obtain permission directly from the copyright holder.

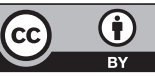

